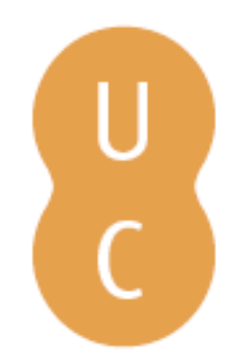

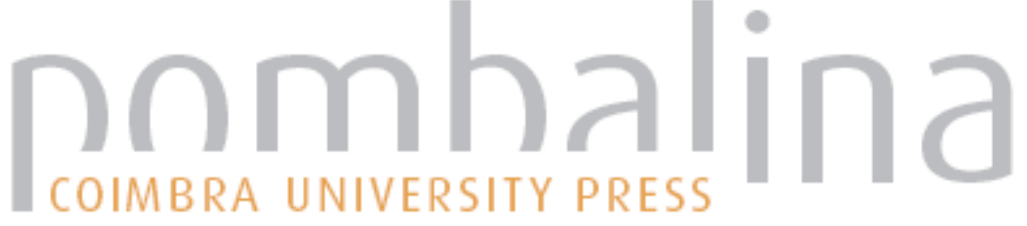

\section{Investigation of slope thresholds for flame attachment}

Autor(es): $\quad$ Sharples, Jason J.; Edgar, Ross; Sidhu, Harvinder S.

Publicado por: Imprensa da Universidade de Coimbra

URL

persistente:

URI:http://hdl.handle.net/10316.2/44524

DOI:

DOI:https://doi.org/10.14195/978-989-26-16-506_7

Accessed : $\quad$ 26-Apr-2023 09:30:45

A navegação consulta e descarregamento dos títulos inseridos nas Bibliotecas Digitais UC Digitalis, UC Pombalina e UC Impactum, pressupõem a aceitação plena e sem reservas dos Termos e Condições de Uso destas Bibliotecas Digitais, disponíveis em https://digitalis.uc.pt/pt-pt/termos.

Conforme exposto nos referidos Termos e Condições de Uso, o descarregamento de títulos de acesso restrito requer uma licença válida de autorização devendo o utilizador aceder ao(s) documento(s) a partir de um endereço de IP da instituição detentora da supramencionada licença.

Ao utilizador é apenas permitido o descarregamento para uso pessoal, pelo que o emprego do(s) título(s) descarregado(s) para outro fim, designadamente comercial, carece de autorização do respetivo autor ou editor da obra.

Na medida em que todas as obras da UC Digitalis se encontram protegidas pelo Código do Direito de Autor e Direitos Conexos e demais legislação aplicável, toda a cópia, parcial ou total, deste documento, nos casos em que é legalmente admitida, deverá conter ou fazer-se acompanhar por este aviso. 


\section{ADVANCES IN}

\section{FOREST FIRE RESEARCH}

\section{8}

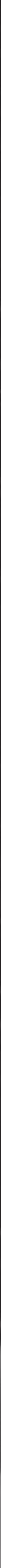




\title{
Investigation of slope thresholds for flame attachment
}

\author{
Jason J. Sharples*; Ross Edgar; Harvinder S. Sidhu \\ School of Physical, Environmental and Mathematical Sciences, UNSW Australia. \\ \{j.sharples@adfa.edu.au*\}
}

\begin{abstract}
It is well known that wildfires, burning in the landscape, spread more rapidly as the slope of the terrain increases. Typically rules of thumb are employed to provide guidance on expected rates of spread on slopes up to about twenty degrees. For slopes inclined above twenty degrees, however, fire behaviour is more difficult to predict. Currently, the reasons for this are not well understood and there is no definitive model (operational or otherwise) that can account for the types of fire behaviour observed on very steep or confined topography. This behaviour includes so called eruptive fire behaviour, which is characterized by dynamic fire propagation - the fire can accelerate up the slope to very high rates of spread, sometimes with tragic consequences. In this paper we present the results of computational fluid dynamics analyses of convective plume dynamics in a rectangular trench similar to those involved in the Kings Cross Underground disaster. We demonstrate the existence of a threshold angle of inclination, above which the convective plume attaches to the floor of the trench. We discuss the implications of our results for wildland fire safety.
\end{abstract}

Keywords: Eruptive fire behaviour, plume attachment, flame attachment, computational fluid dynamics, slope, dynamic fire propagation.

\section{Introduction}

It is well known that wildfires, burning in the landscape, spread more rapidly as the slope of the terrain increases. Consequently, knowledge of how a fire will spread on slopes in the landscape is an important aspect of wildfire risk management. However, there have been very few systematic studies of slope-driven landscape fires, and no definitive account of the driving processes has been forthcoming. Nevertheless, a number of methods for accounting for the effects of slope on rate of wildfire spread are employed in modelling frameworks and there has been considerable effort put into laboratory-scale studies.

Laboratory-scale studies have also been utilised in examining the nature and causes of fire spread in building structures. Examples include those performed as part of the investigation into a disastrous fire that engulfed an escalator in Kings Cross, London and killed 31 people. Despite initial assessments, which revealed nothing to suggest that it would rapidly develop (Crossland 1992), the fire suddenly spread with extreme ferocity up the escalator trench and into the ticket hall and surrounding areas. Investigations into the King's Cross fire revealed that the extreme fire growth was primarily caused by a distinct phenomenon, subsequently termed 'flame attachment', whereby the buoyant convective plume containing the flames and combustion products attaches to the surface. In a number of instances eyewitnesses and fire investigators described the fire behaviour associated with flame attachment as 'eruptive' (Drysdale et al. 1992).

The term 'eruptive' has also been used to describe certain instances of wildfire behaviour (Viegas 2006). Such instances exemplify a very dangerous aspect of wildland fire behaviour; they pose a significant threat to the safety of wildland fire-fighters and complicate the broader problem of wildfire risk management in landscapes prone to their occurrence. Currently, there is no definitive model (operational or otherwise) that accounts for eruptive fire behaviour. However, studies addressing the incidence of eruptive fire behaviour have revealed that eruptive events are more likely to occur on steep slopes and in canyons. In particular, Viegas and Pita (2004) indicated that eruptive fire behaviour occurred whenever a canyon was sufficiently steep or sufficiently closed. Similarly, the vast majority of eruptive wildfire events have taken place in canyons and on steep slopes. Thus, observations of 
eruptive fire behaviour have suggested the existence of a set of geometric precursors that are necessary for, or at least enhance the likelihood of, an eruptive event.

Similarly, experimental and theoretical investigations conducted after the King's Cross fire indicated that flame attachment was strongly dependent on the surface geometry. Indeed, it was found to more rapidly cover surfaces that were steeper, and to occur more readily in more enclosed, 'trenchlike' configurations. In particular, flame attachment was investigated using state-of-the-art computational fluid dynamics modelling by Simcox et al. (1992), who investigated the phenomenon in a rectangular trench inclined at $30^{\circ}$. In doing so, Simcox et al. (1992) were able to confirm that flame attachment did indeed occur in such a configuration. However, Simcox et al. (1992) did not consider similar trench geometries inclined at angles below $30^{\circ}$, and so were unable to confirm the existence of a slope threshold for flame attachment similar to that which had been identified in experimental studies.

In this paper, we therefore report on a numerical study of the flow of convective plumes in a trenchlike configuration similar to that studied by Simcox et al. (1992), but at lower angles of inclination and various energy intensities.

\section{Computational Fluid Dynamics (CFD) Model}

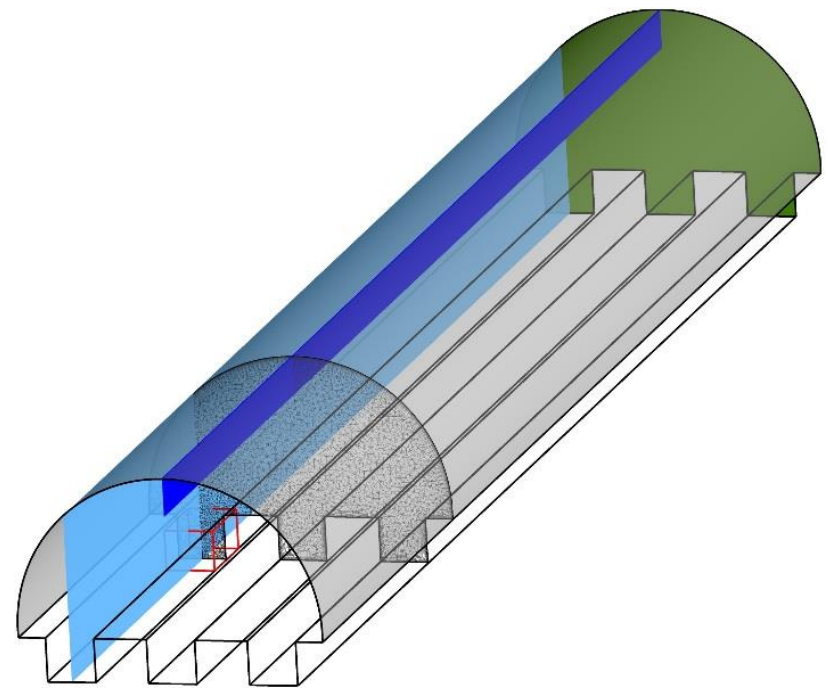

Figure 1 - The flame attachment domain of the tunnel with three escalator trench numeric model. The upper tunnel openning is shaded green and the roof is shaded grey with a semi-transparent rendering. The fire source volume is outlined in red and later figures, i.e. the flow field results in Figures 2 and 3, show results on the light and dark blue two dimensional virtual planes viewed from a normal angle. Another virtual plane orthogonal to the latter pair is shown cutting through the fire volume to reveal the size of three dimensional mesh element crosections like fine lace through the interior of the domain.

The interaction of variables within a dynamic flow field are well described by the Navier-Stokes equations that were derived during the first half of ninteenth century and are today generally understood to include the mass, momentum and energy conservation relations. Being highly non-linear second order partial differential equations, a systemmatic method of finding analytic solutions to describe turbulent regions of fluid problems have not been found other than for a few exceptional situations far removed from fire driven convective states of relevance to this study. By contrast, computational methods are able to replace the intractable differential continuum relations with discrete linear algebraic approximations that are then solved simultaneously for the discetised geometry and then repeatedly for the required sequence of discrete timesteps needed to deterministically evolve the transient flow field from its initial to subsequent states. 
We employ a computational model domain based on a subset of the King's Cross underground complex as shown in Figure 1. In particular we use only the tunnel section of the domain used by Simcox et al. (1992).

Identical geometry and mesh were used for all tunnel domain inclinations, which was defined by the alignment of the geometry with the gravity vector. Simulations were run with tunnel inclinations of $18^{\circ}, 20^{\circ}, 22^{\circ}, 24^{\circ}, 26^{\circ}, 28^{\circ}$ and $30^{\circ}$.

The fluid within the model domain is defined as an ideal gas having the physical and thermal properties of air at $25^{\circ} \mathrm{C}$ and $1 \mathrm{~atm}$ pressure.

The fire is modelled as a thermal energy source that fills the volume of the left escalator trench to a height of $0.9 \mathrm{~m}$ and extends from $10 \mathrm{~m}$ to $12 \mathrm{~m}$ inside the lower entrance of the $42 \mathrm{~m}$ long tunnel. To mimic flames, the fire source volume was divided tunnelwise into eight sections with alternating sets of four sections releasing the fire's energy and swapping with each other at $50 \mathrm{~Hz}$.

The tunnel surfaces were all defined as smooth, no-slip adiabatic walls. The tunnel ends were both defined as openings which had defined zero average relative pressures and turbulence gradients. Air could freely move in or out of the openings however when entering was constrained to travel normal to the boundary and have a temperature defined according to the adiabatic lapse rate of the system.

All simulations started from a condition of zero flow.

The model initialisation conditions, boundaries and discretisation scales were validated by special simulations, e.g. no flow developed when the fire energy source was $0 \mathrm{~W}$ and smaller discretisation of the spatial and temporal scales reinforced the observed outcomes associated with the baseline model.

The resulting convectively-driven flow was calculated using the CFD package ANSYS CFX (ver. 17) with empirically derived "baseline Reynolds Stress Model (RSM)" equations approximating turbulence details (ANSYS, 2015). The RSM is superior to the standard Reynolds Averaged NavierStokes (RANS) models because it has individual transport equations for all six independent components of the Reynolds stress tensor instead of assuming it is isotropic with one. The RSM is thus well suited to model fire plumes which are turbulent and exhibit significant directional differences in viscosity proportional to their directional rates of strain.

As with the most advanced SST two equation RANS models, the baseline RSM also solves the wall distance of geometry elements and transforms from a turbulence-dissipation (or $\varepsilon$ in the $k-\varepsilon$ RANS model where $k$ is turbulence-energy) to turbulence-frequency (or $\omega$ in the $k$ - $\omega$ RANS model) representation of the conservation equations to better capture the influence of the viscous sub-layer on the flow field variables close to walls.

\section{Results}

The simulated flows had significant features in common despite the broad range of tunnel inclinations and fire energy levels examined. The hot plume from the fire source initially rose vertically towards the tunnel ceiling. At later stages, and significantly much later stages for simulations with lower fire source energy and/or tunnel slope angles, the base of the vertically rising plume started to attach to the floor of the trench and work its way along that surface with a laminar flow pattern for about $10 \mathrm{~m}$ (in the case of the geometry studied) until being dissipated or squeezed out to the trench sides.

Figure 2 shows simulation results for the fire source energy equal to $431 \mathrm{~kW}$ runs at typical later stages of flow field development. Parameters of the simulations are listed in individual text headers and a pair of vertical planes of the three dimensional geometry are shown for each: i.e. through the centre of the fire trench escalator (at the bottom of each pair with fine black line showing top of the escalator trench); and for the top part of the pair the top part of the tunnel centre plane. The planes are 
coloured by the velocity component in the tunnelwise direction with superimposed grey shaded temperature contours.

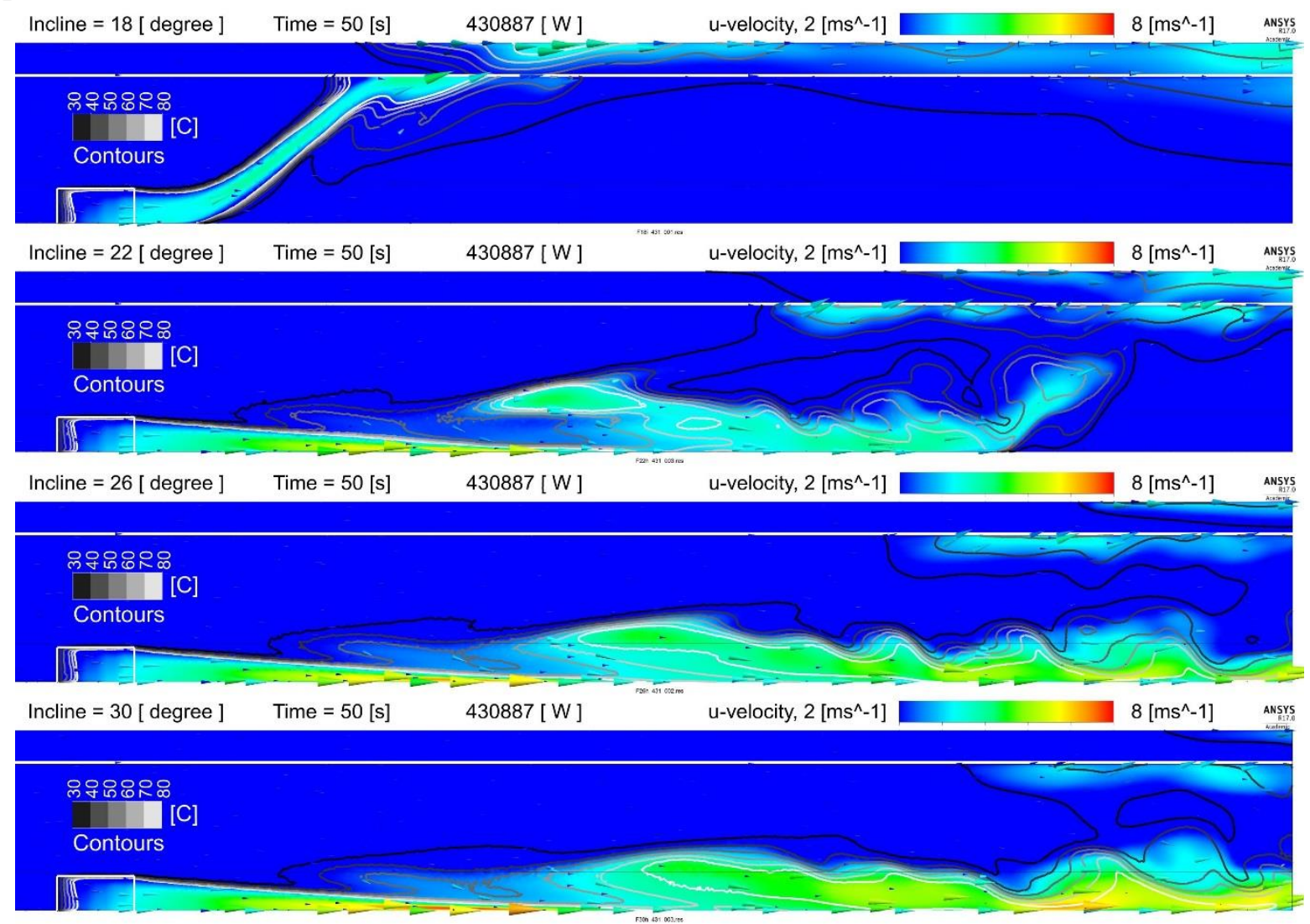

Figure 2 - Flame attachment in trenches has similar characteristics over the broad range of tunnel slopes simulated. The tapering laminar flow from the fire source runs about $10 \mathrm{~m}$ towards the trench floor, given a longer time for the lower slopes, before being squeezed out to the trench sides and continuing along the full length of the trench, however with increasing turbulence at lower slope angles.

Figure 3 shows the laminar boundary layer of flows in the $26^{\circ}$ slope tunnel 26 heading towards the escalator trench floor over the significant range of fire source energies simulated. The laminar boundary layer is eventually squeezed or pushed out to the sides after about $10 \mathrm{~m}$ just as it was for the tunnel slope range shown in Figure 2. Also similarly, the flame attachment along the sides of the escalator trench eventually reached the end of the tunnel however took longer and was associated with less turbulence for lower fire energy source levels. 


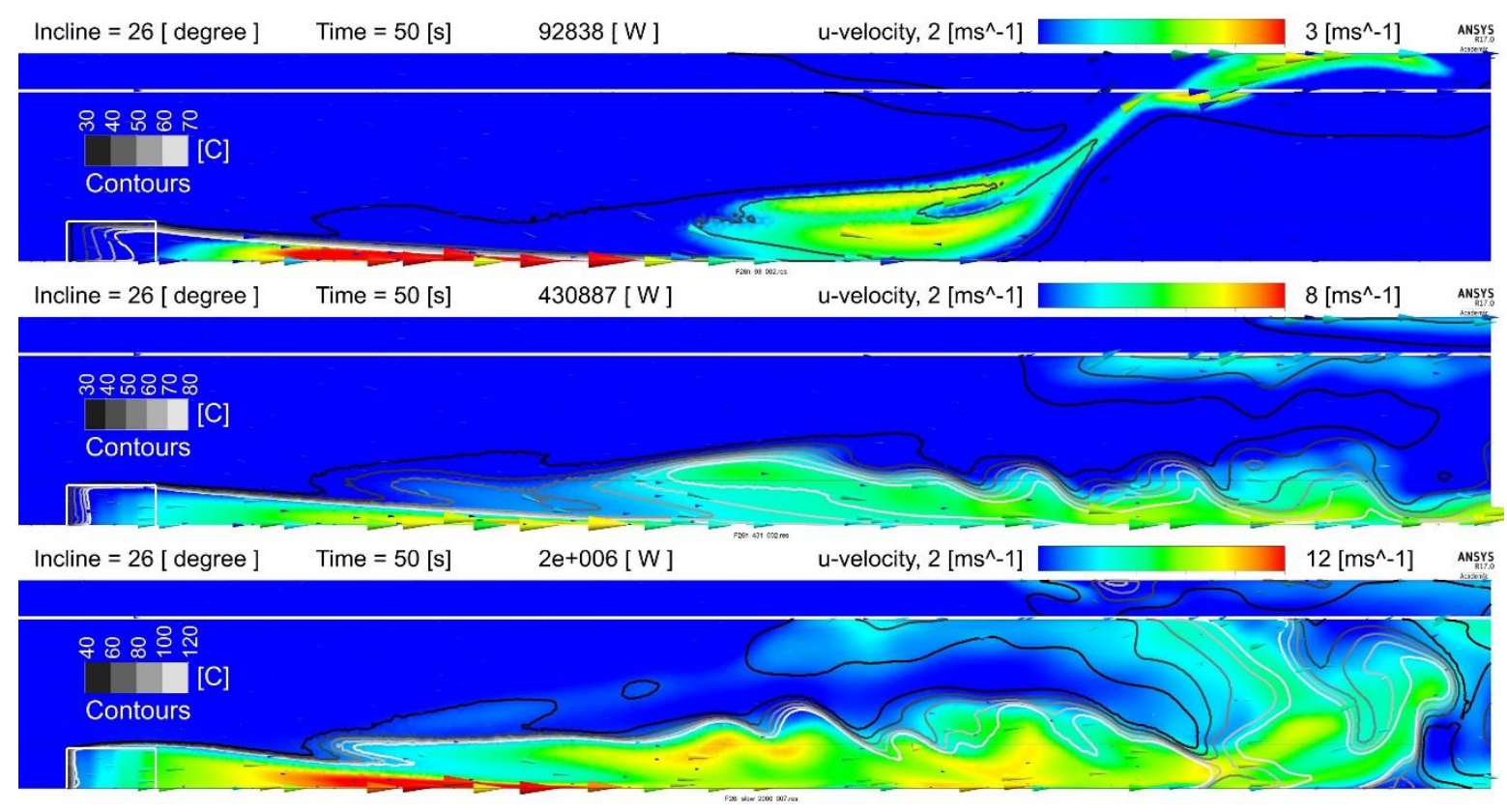

Figure 3 - Flame attachment in the trenches has similar characteristics over the broad range of fire source energies simulated. The tapering laminar flow from the source typically runs about $10 \mathrm{~m}$ towards the trench floor, given a longer time for lower energies, before being squeezed out to the trench sides and continuing with increasing turbulence at higher energy levels. The plume of the $92838 \mathrm{~W}$ source would be expected to attach along the full length of the tunnel's trench and be less turbulent than the higher fire energy sources shown if the simulation time were extended.

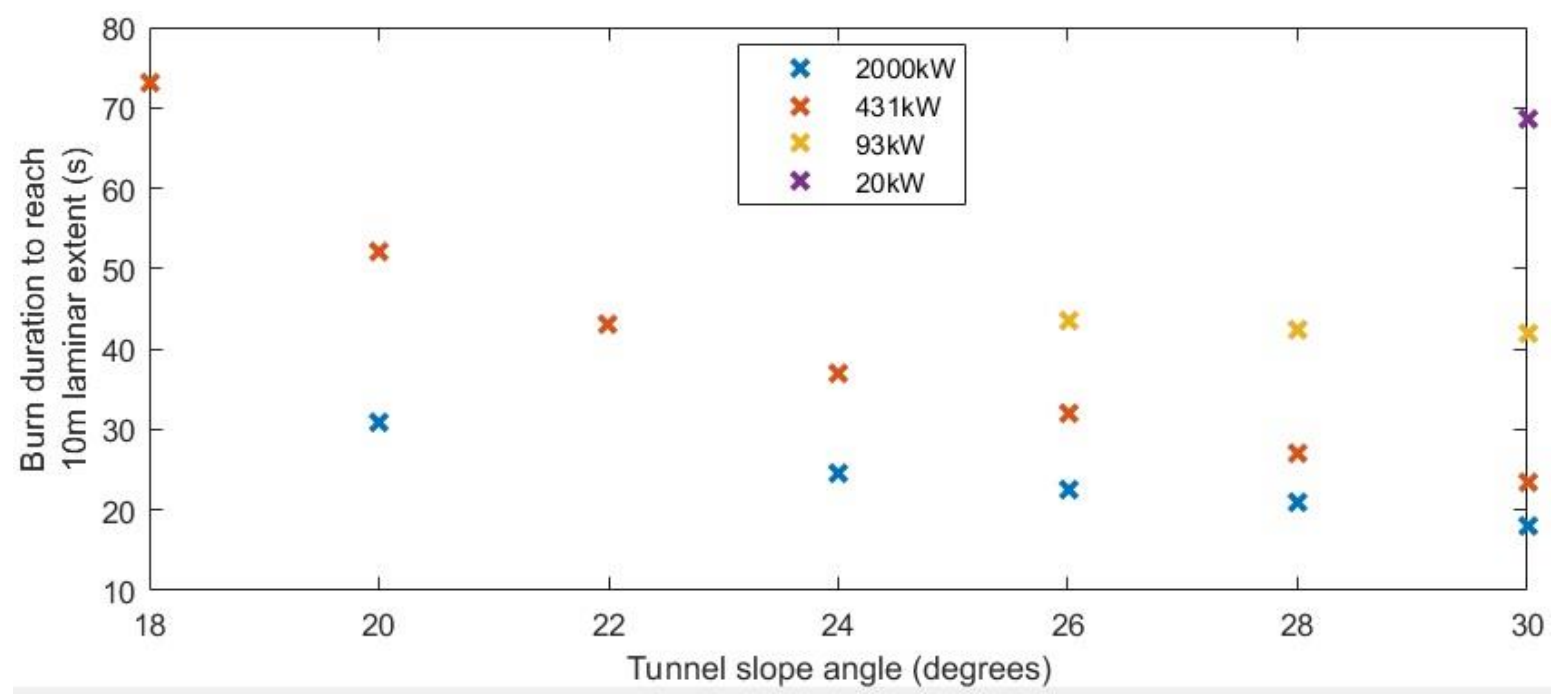

Figure 4 - Simulation time taken for flame attachment to work its way up the escalator trench to point when its laminar boundary layer depth was squeezed out to the trench sides, or $10 \mathrm{~m}$ for the geometry of the tunnel trench considered.

Figure 4 shows the time taken for the flame attachment, or hot plume, to work its way along the floor of the trench to the point of its laminar boundary layer depth being squeezed out to the sides, generally $10 \mathrm{~m}$ as stated earlier for the tunnel trench geometry considered. The escalator trench was $1.0 \mathrm{~m}$ high and $1.1 \mathrm{~m}$ wide (i.e. out of the page in the sense of Figures 2 and 3).

Depending on the combination of tunnel slope and fire source energy, the hot plume subsequently either remained attached to the trench sides, reinforcing a laminar flow across the entire trench section, 
or broke away from the top corners of the trench in turbulent waves rising to the tunnel roof. The latter occurs when the tunnel slope is too low to keep the buoyancy force in check and hot plumes are able to rise with less momentum loss when detaching from the upper corners of the trench despite the implicit turbulence that entails.

In terms of simplistic analogies, drawn from the well studied Coandă effect, it may be useful to think of the surfaces of the trench as the most efficient hot plume transport channel available for the flow from low to upper tunnel heights because of the laminar flow conditions that dominate (and involve far less momentum loss than turbulent flow) for a significant boundary layer depth there. However, if the vertical buoyancy force overwhelms the inertial advantage of remaining within the trench surface flow's laminar sublayer, then hot plumes will detach from surfaces to better placate the buoyancy drivers.

Because the physics of the flow along the surfaces of the tunnel and trench have a determinant influence on the behaviour of the plume, it is imperative that the simulation's manner of modelling the wall flow properties is robust. To ensure this was the case:

- independent transport equations were solved, using the RSM, for each of the independent Reynolds stress tensor components and so the viscous sublayer stress of flows near surfaces varied directionally to reflect that surface's gradient;

- twenty-two prism element inflation layers were placed on all tunnel surfaces, when discretising the fluid's geometry (expanding at the rate of 1.2 from a first layer height of $0.75 \mathrm{~mm}$ ), to produce a smooth transition to the maximum $200 \mathrm{~mm}$ side length unstructured tetrahedral elements of the free stream and to keep the critical $y^{+}$first element centroid's wall distance below the critical threshold of 30 required to properly use the ANSYS CFX wall model equations (ANSYS 2017);

- the maximum root mean square average Courant number of the flow in the simulations, which measures the number of discrete element lengths the flow would traverse in one discrete timestep duration, was kept near one so that the properties of each element along each flow path had the opportunity to influence the flow field's development in the sequential manner a physically meaningful evolution of the flow requires (Courant et al, 1928).

In the simulation space, the upper corner of the escalator trench represents an extremely sharp discontinuity where two surfaces meet at a right angle. Flow there is difficult for the model to capture accurately since element sizes are minute and the courant number rises well above one. In order to accurately simulate the influence of this sharp edge on the flow, a much shorter discretisation time scale, i.e. timestep, needed to be used for the faster $2000 \mathrm{~kW}$ fire energy source conditions. For example, the $30 \mathrm{~ms}$ time steps used for the simulations generally needed to be shortened to $3 \mathrm{~ms}$ for the $2000 \mathrm{~kW}$ fire energy source tunnels to show the flow was consistently drawn $10 \mathrm{~m}$ towards the trench floor before breaking away from trench sides in plumes. At the longer discretisation time scale the hot plumes would break away earlier and disrupt the otherwise consistent laminar flow from the height of the source to the escalator floor $10 \mathrm{~m}$ further up the tunnel.

\section{Conclusion}

The results of this study provide further support for the notion that plume attachment is essentially a geometric phenomenon - it arises as a consequence of the interaction between the convective plume and the geometry of the inclined surface.

Wu et al. (2000) reported finding a critical angle of attachment between $24^{\circ}-26^{\circ}$ when considering flames on inclined planar surfaces. In CFD simulations by Simcox et al (1992) flame attachment in a $30^{\circ}$ sloping tunnel trench was found at the upper range of the energy levels we studied and for various

Advances in Forest Fire Research 2018 - Page 86 
pressure driven inlet flow conditions; however, other slopes were not considered. In a separate study we considered the effect of the intensity of the convective plume and found very similar results to those reported here (Edgar et al, 2015). Overall, the indication is that the plume attachment phenomenon is independent of the convective intensity of the plume, at least for intensities up to the order of a megawatt per cubic metre. Despite this, the rapidity with which the fire progresses up the slope does vary, and is significantly faster for higher intensities at least up to that at which wildfires could be expected to burn. As such, plume attachment should be considered as a distinct likelihood for fires burning in landscapes that are sufficiently inclined and more so when also enclosed; for example, like a canyon or gully. As such, these findings have strong implications for fire safety in wildland fire environments.

With the developed simulation model confidently working following validation of the discretisation scales used, it may now be readily extended to the study of other geometry trenches in tunnels and open fields more consistent with conditions encountered during wildfires.

\section{Acknowledgement:}

This research was funded by an Australian Research Council (IN140100011), and undertaken with the assistance of resources provided at the NCI National Facility under the Australian Government National Computational Merit Allocation Scheme.

\section{References:}

ANSYS Inc. ANSYS CFX Modelling Guide - release 17.0. 2015.

Courant R, Friedrichs K, Lewy H. Uber die patiellen differenzengleichungen der mathematischen physic 1928; Translation: on the partial difference equations of mathematical physics 1967; Mathematische Annalen 100 (1): 32-74; Translation - IBM Journal March 1967: 215-234.

Crossland, B. (1992) The King's Cross Underground Fire and the setting up of the investigation. Fire Safety Journal 18, 3-11.

Drysdale, D.D., Macmillan, A.J.R. (1992) Flame spread on inclined surfaces. Fire Safety Journal 18, 245-254.

Edgar RA, Sharples JJ, Sidhu HS. Revisiting the King's Cross Underground disaster with implications for modelling wildfire eruption, 21st International Congress on Modelling and Simulation Modelling and Simulation Society of Australia and New Zealand 2015: 215-221.

Simcox S, Wilkes N, and Jones L. Computer simulation of the flows of hot gases from the fire at King's Cross underground station. Fire Safety Journal 1992. 18 (1): 49-73.

Viegas, D.X., Pita, L.P. (2004) Fire spread in canyons. International Journal of Wildland Fire 13, 253274.

Viegas, D.X. (2006a) Parametric study of an eruptive fire behaviour model. International Journal of Wildland Fire 15, 169-177.

Wu, Y., Xing, H.J., Atkinson, G. (2000) Interaction of fire plume with inclined surface. Fire Safety Journal 35, 391-403. 